\title{
Uma fotografia, múltiplas imagens: a educação rural no norte do Brasil
}

\author{
One photograph, myriad images: rural education \\ in Northern Brazil
}

\section{Sonia Maria da Silva Araújo}

Docente do Programa de Pós-graduação do Instituto de Ciências da Educação e coordenadora do grupo de pesquisa Constituição do Sujeito, Cultura e Educação/Universidade Federal do Pará

Instituto de Ciências da Educação / UFPA

Av. Bernardo Sayão, $s / n$

66075-900 - Belém - PA - Brasil somentesonia@hotmail.com
ARAÚJO, Sonia Maria da Silva. Uma fotografia, múltiplas imagens: a educação rural no norte do Brasil. História, Ciências, Saúde - Manguinhos, v.17, n.4, out.-dez. 2010, p.1009-1022.

\section{Resumo}

Aborda os processos de constituição e institucionalização de escolas nas fazendas de criação extensiva localizadas na ilha de Marajó, interior de Soure, Brasil, e demonstra que eles ocorreram associados à grande propriedade e a relações políticas estabelecidas entre fazendeiros, vaqueiros e poder público. Refexões teóricas, dados sociais e acontecimentos somam-se a imagens fotográficas que revelam a fragilidade da educação pública oferecida às crianças das zonas rurais do extremo norte do país.

Palavras-chave: escolas de fazenda; educação pública; Marajó (PA); Brasil.

\section{Abstract}

The article addresses the processes by which schools have been established and institutionalized on extensive-grazing ranches in rural Soure, Marajó Island, Brazil. Emergence of these schools has been tied to large landholdings and to the political relations between ranchers, vaqueiros, and government. Theoretical reflections, social data, and events are placed side-by-side with photographs that depict the fragile state of public education available to children living in the rural areas of far northern Brazil.

Keywords: schools; ranches; power; subalternization; Marajó; Brazil. 
Sonia Maria da Silva Araújo

$\mathrm{R}$ aymond Williams (1989), escritor e crítico literário inglês e fundador, com Hobsbawm, da New Left, foi atuante no campo da educação de adultos e desenvolveu o projeto Worker's Education Association (WEA). Ele entendia ser de longa duração o processo de transformação das sociedades capitalistas, para garantir condições dignas de vida à classe trabalhadora, devendo a alfabetização nele ocupar lugar de destaque (Williams, 1961). Para o autor, falecido em 1988, bens culturais como a escola só podem ser entendidos no contexto das relações sociais, isto é, em meio às instituições, ao poder e à economia.

Paulo Freire, proeminente educador brasileiro, já na década de 1940 defendia um tipo de educação para a libertação, capaz de tornar a sociedade brasileira consciente de sua história. Tendo colocado em prática uma pedagogia contra a opressão, acreditava que a educação no Brasil "haveria de ser corajosa, propondo ao povo a reflexão sobre si mesmo, sobre seu tempo, sobre suas responsabilidades" (Freire, 1977, p.59). Em sua opinião, o silenciamento e a "educação bancária" promoveram, especialmente nas regiões mais atrasadas do país, uma consciência colonizada e ingênua, que só poderia ser ultrapassada com educação pautada no diálogo.

No Brasil, o processo de construção da dignidade da classe trabalhadora, tão especulada por Williams, está, em alguns espaços do sertão do país, muito distante de apresentar mudanças substanciais. Os poucos dados existentes a respeito do trabalho escravo embora muito tenha sido feito ${ }^{1}$ - indicam números alarmantes. A Organização Internacional do Trabalho (OIT, 2005) estima que, no Brasil, cerca de 25 mil trabalhadores vivem em situação de trabalho escravo, a maioria nos estados do Pará e Mato Grosso. A infância, que deveria ser contemplada com políticas públicas de intervenção e fiscalização nas áreas de saúde e educação (alfabetização), ainda não recebeu a atenção que merece. Segundo o Fundo das Nações Unidas para a Infância (Unicef, na sigla em inglês), em cada mil crianças nascidas vivas no Brasil, 33 morrem sem completar cinco anos. No Norte do país ainda existem dois milhões de crianças em faixa etária própria à educação infantil sem acesso à creche (Unicef, 2008).

O estudo aqui reportado teve como objetivo compreender o processo de constituição e institucionalização da escola no interior das fazendas da ilha de Marajó, no estado do Pará. Quando sua pesquisa empírica foi realizada, em 2001 - portanto quase meio século depois das considerações de Williams e das experiências sociais de alfabetização empreendidas por Paulo Freire no Nordeste brasileiro -, constatou-se a difícil realidade em que se encontram trabalhadores e trabalhadoras da Amazônia paraense, ao ver suas crianças submetidas a degradantes condições educacionais e de saúde.

A Confederação Nacional dos Bispos do Brasil (CNBB) há anos vem denunciando o estado vulnerável em que se encontra a infância em Marajó, especialmente no que diz respeito à prostituição infantil. O bispo dom José Luiz Ascona, que há mais de vinte anos está à frente da prelazia na ilha, denuncia o descaso do poder público e divulga o que toda a gente da região de Marajó sabe: que crianças se prostituem em troca de comida ou de alguns trocados. O próprio Ministério Público do Estado do Pará reuniu-se, em 2007, para discutir estratégias de combate à exploração sexual de crianças e adolescentes na localidade. ${ }^{2}$

Marajó, arquipélago que abriga a maior ilha fluvial do mundo, está localizado no delta do rio Amazonas, no extremo norte do estado do Pará, próximo da linha do Equador. 
Sua área mede, segundo o IBGE, aproximadamente, $49.606 \mathrm{~km}^{2}$. A ilha se compõe de três microrregiões: Portel, Furos de Breves e Arari. Desde o século XVII o arquipélago esteve sujeito à exploração de seus recursos naturais, como a extração da madeira. Após a devastação quase completa do mogno na microrregião de Furos de Breves, os madeireiros dirigiram-se para a de Portel, que ainda conta com matéria-prima de alto valor comercial. Devido à ausência do Estado na região, a prática da extração, sem qualquer fiscalização ou controle, já provocou, entre outros graves problemas, a mutilação de centenas de corpos, uma vez que, para a derrubada das árvores, as madeireiras contratam nativos da região sem qualquer experiência com o manuseio de motosserras. Na microrregião de Arari, município de Soure, lugar em que se efetuou o estudo em questão, encontram-se as fazendas de criação extensiva. A extração da madeira e a pecuária são os grandes responsáveis pelo trabalho escravo no estado do Pará. ${ }^{3}$

\section{As terras e suas gentes transformadas e subjugadas}

Conforme mencionado, este artigo baseia-se em estudo mais amplo, "Cultura e educação na ilha de Marajó: um estudo com base em Raymond Williams", que é fundamentado epistemologicamente no marxismo culturalista dos cultural studies e bibliograficamente em estudos de temas que lhes são adjacentes, como cultura brasileira, colonização do Brasil, história da ocupação da Amazônia e antropologia dos índios e mestiços do Brasil. Metodologicamente, abrangeu pesquisa de campo realizada nas seis fazendas do município de Soure, todas incluindo escolas em suas terras: Santa Cruz da Tapera, Matinadas, Flecheiras, São Lourenço, Cuieiras e São Bento. ${ }^{4}$ Para a recolha de dados, realizamos entrevistas com a secretária de Educação do município e assessoria responsável pelas escolas das fazendas, professores, ex-professores, fazendeiros e pais e mães de alunos, e fizemos observação direta. Dados complementares foram coletados junto à Secretaria de Agricultura do Estado do Pará (Sagri), ao Instituto Brasileiro de Geografia e Estatística (IBGE), ao arquivo da Prefeitura de Soure, ao Museu Paraense Emílio Goeldi e ao Instituto Histórico e Geográfico do Pará.

Para o alcance do escopo deste artigo, isto é, apresentar imagens que demonstrem como a escola se constituiu e instituiu nas fazendas de criação extensiva na ilha de Marajó, de modo a revelar as relações entre educação, poder público e economia, trazemos, do material coletado em campo, apenas extratos de entrevistas com uma ex-professora de escola de fazenda e uma proprietária.

A imagem, neste estudo, constitui uma ferramenta de "efeito de realidade", conforme expõe Roland Barthes (1990), para quem a fotografia "como um análogo mecânico do real, traz uma mensagem primeira que, de certo modo, preenche plenamente sua substância e não deixa lugar ao desenvolvimento de uma mensagem segunda" (p.12). Sabe-se, contudo, que a imagem fotografada não é uma ilustração da realidade, porém se ela é articulada a um discurso que não se limite a ser sua vibração, pode se tornar um efeito dessa realidade. No caso específico deste estudo, a fotografia é o texto; é parte constitutiva da palavra, do sentido que atribuímos ao que presenciamos e registramos em Marajó. É, portanto, extensão textual, prolongamento de interpretação, crítica da fonte, como defende Burke (2004). 
Esse modo de tratar a imagem fotográfica decorre da compreensão de que, embora ela seja um testemunho, uma evidência histórica por meio da qual se podem ler as estruturas de pensamento e representações de determinada época, não deve ser considerada reflexo puro da realidade, esclarece Burke (2004). Sob esse viés, reconhecemos que as imagens fotográficas aqui utilizadas não são apenas ferramentas, mas também recursos privilegiados de afirmação de um discurso que corre em certa direção. São textos visuais que, articulados ao texto escrito, produzem o sentido que demos à história e à realidade das escolas de fazenda de Marajó. Com Mauad (2008), entendemos a fotografia como resultado de um processo de produção de sentidos e seu uso nas ciências sociais, uma possibilidade de reflexão em meio a infinitas escolhas.

Em Marajó, as fazendas instituídas pelos missionários jesuítas, carmelitas e mercedários a partir da segunda metade do século XVII ofereceram ambiente propício à formação do tipo humano que hoje vive nas fazendas de criação extensiva da ilha - o vaqueiro marajoara, também conhecido como caboclo marajoara. ${ }^{5}$ A princípio, o braço forte que fez organizar e funcionar essas fazendas foi o dos Marauaná, da linhagem dos Aruã, que em contato com portugueses e, depois, com escravos africanos traficados deu origem ao vaqueiro marajoara. Segundo Raymundo Moraes (1936), em Marajó, antes da chegada dos europeus, só havia Aruã e antes deles, somente Marajoara. ${ }^{6}$ Isso se comprova com a descoberta de olaria na ilha, cuja produção é atribuída aos Marajoara e Aruã. Informa ainda o autor que, entre o nordeste e o sudeste de Marajó, há um reino cerâmico abundante em sarcófagos, alguns deles em aterros artificiais, como o do Pacoval, no Arari. Clifford Evans e Betty J. Meggers (1957) destacam o grande refinamento cerâmico dos Marajoara, que construíram os primeiros tesos ${ }^{7}$ em Marajó. Dos achados arqueológicos de olaria, chama especial atenção a produção de tangas dos Marajoara. De formato triangular, a tanga feminina é côncava e ligeiramente abaulada, pintada com desenhos geométricos formando verdadeiras rendas plásticas. Asseguram Gastão Cruls (1955) e Miranda Neto (1976) que as tangas marajoaras são originalíssimas, não tendo sido encontrada peça semelhante em nenhuma parte do mundo.

Eduardo Galvão $(1966,1979)$ identifica o período de 1600 a 1759 como o primeiro momento do contato entre a sociedade luso-brasileira e a indígena na Amazônia. A expansão portuguesa na região foi marcada pelo estabelecimento de feitorias e missões, expedições de reconhecimento e ocupação, resgates, guerras justas e descimentos de índios para os centros coloniais.

A princípio, a presença de holandeses, espanhóis e franceses foi o argumento utilizado pelos portugueses para travarem guerras na região, seguido da conquista do território invadido e, em consequência, da 'caça' aos Aruã. Depois, com a invasão consolidada, no século XVIII e na primeira metade do século XIX, outras lutas foram travadas em nome da 'guerra justa', e a ação dos portugueses foi a escravização. Por fim, na segunda metade do século XIX e por todo o seguinte, já com grupo humano miscigenado, em que a figura aruã se havia perdido e o vaqueiro se constituído, a diretriz foi garantir mão de obra para o trabalho na fazenda. Para tanto, a ação dos fazendeiros consistiu em sedimentar a servidão, o afilhadismo e o compadrio, tornando as gentes de Marajó dependentes de seu favor. A prática, por exemplo, instalada já no século XX, de doação de crianças para 
serviços domésticos às famílias dos fazendeiros na cidade de Belém - os filhos de criação é demonstração desse tipo de relação.

Como esclarece Canclini (1998), a colonização produziu, na América Latina, três segmentos sociais: o dos latifundiários, o dos escravos e o dos 'homens livres'. Este último, segundo o autor, não era proprietário nem proletário e dependia materialmente do favor de um poderoso, e foi assim que o favor se estendeu a outras áreas da vida social. Em Marajó, as relações sociais entre fazendeiro e vaqueiro, fazendeiro e poder público, vaqueiro e poder público são uma demonstração de um processo que, no plano da vida social dos Estados latino-americanos, produz modos arcaicos de interação, que promovem a dependência. Na opinião de Canclini, "o favor é tão antimoderno quanto a escravidão, porém 'mais simpático' e suscetível de unir-se ao liberalismo por seu componente de arbítrio, pelo jogo fluido de estima e autoestima" (p.76).

A fazenda, no Brasil, resultou da união entre terra e família. Trata-se de um sistema oriundo de Portugal, em que a unidade da família se prolongava ou estendia sobre o sistema de propriedade. Família e propriedade eram ramos da mesma organização social, a primeira representando o patriarcalismo quase feudal da vida familiar e a segunda, o esteio da vida econômica. Esse modelo tipicamente lusitano foi reforçado pela política de sesmarias, e as fazendas de criação extensiva em Marajó são representantes fiéis dele (Diégues Júnior, 1960, 1979).

O que chama atenção, nessas fazendas, é a extensão. São verdadeiros latifúndios perpetuados pelo direito de herança e criados, como explica Leonardi (1996) ao tratar do latifúndio no Brasil, sob o signo da violência contra populações nativas. As antigas propriedades coloniais até hoje permanecem nas mãos das mesmas famílias, em sucessão patrilinear. No Pará, diz Vicente Salles (1971), são relativamente raras as disputas judiciais em torno das grandes propriedades rurais, "e as partilhas, quando ocorrem, se fazem amigavelmente, e de modo geral ainda o filho mais velho conserva a sede, ou casa-grande" (p.118). Veremos adiante que o depoimento de dona Dita ${ }^{8}$, proprietária, em 2001, da fazenda Santa Cruz da Tapera que instituiu ali a escolarização, ilustra com propriedade essa assertiva quando declara: "Meu marido é que tinha fazenda. Meu sogro comprou no dia 5 de maio de 1910. Aqui, na época, era a fazenda Tapera ... que o meu sogro comprou a fazenda na época. A sesmaria era São Luiz". ${ }^{9}$

É, portanto, sob a regência da fazenda que se estabelecem escolas no interior do município de Soure, no estado do Pará.

\section{Escola de fazenda, poder e esperança}

A institucionalização da escola no interior da fazenda de dona Dita Acatauassu, localizada no interior de Soure, ocorreu na década de 1930, quando ela e o marido, o engenheiro civil Domingos Acatauassu - seu Domingos - foram lá morar para administrar a fazenda. Na década de 1970, com a morte do proprietário, o espólio foi dividido em cinco fazendas: Santa Cruz da Tapera, Aruãs, Filhos de Eva, Ritlândia e São Lourenço. Por ocasião dessa divisão, seu Domingos já possuía outra fazenda, a Maria dos Anjos. 
Quando dona Dita chegou à fazenda Santa Cruz da Tapera, mais precisamente em 1934, constatou que as pessoas não sabiam ler nem escrever e propôs ao marido instalar ali uma escola. Os adultos analfabetos e as crianças da fazenda foram alfabetizados, em princípio, por dona Dita e seu Domingos. Os alunos vieram de todos os lados. Com a notícia de que havia escola na Tapera, as crianças dos campos de Soure começaram a aparecer, vindas de seus 'retiros' ${ }^{10}$ e de outras fazendas. As que não moravam na vila da sede da fazenda e as de outras fazendas (que não tinham como percorrer diariamente a longa distância até a escola) passaram a morar com as famílias dos vaqueiros da própria Tapera. Tal prática tornou-se comum nos campos de Marajó. Nas fazendas com escola, as famílias dos vaqueiros abrigavam, durante todo o ano letivo, crianças de outras fazendas. Tereza, ex-professora da Tapera, explica como isso funcionava: "As crianças ficavam nas casas de parentes, na casa de amigos dos pais... morando ... de março a junho ... Em julho ... iam embora para casa ... Em agosto ... voltavam e ficavam até dezembro". ${ }^{11}$

As crianças 'agregadas' ajudavam a família que as acolhia nos serviços domésticos. Para aquelas que por algum motivo não podiam deixar suas famílias, dona Dita constituiu pequenas escolas em seus retiros, que acabaram transformadas em outras fazendas, com a divisão da Tapera:

Em cada uma [fazenda] eu plantei uma escola. Tinha uma na Filhos de Eva, que meu cunhado fechou ...; tinha uma na São Lourenço, que perdura até hoje; tinha uma na Tapera, que era minha; tinha uma na Flecheiras, que era do Alberto, meu cunhado, que o Fernando, filho dele, toma conta; tinha no Aruãs, que o Paulo Sergio Acatauassu tomava conta. Tem cinco não é? ... Que foi minha, na Maria dos Anjos, que eu vendi para o doutor Roberto Fonseca, mas ele foi bacana, continuou com a escola, com professora e tudo. Seis. E tinha uma... onde era mais? ... Eram sete escolas, que eu dividi.

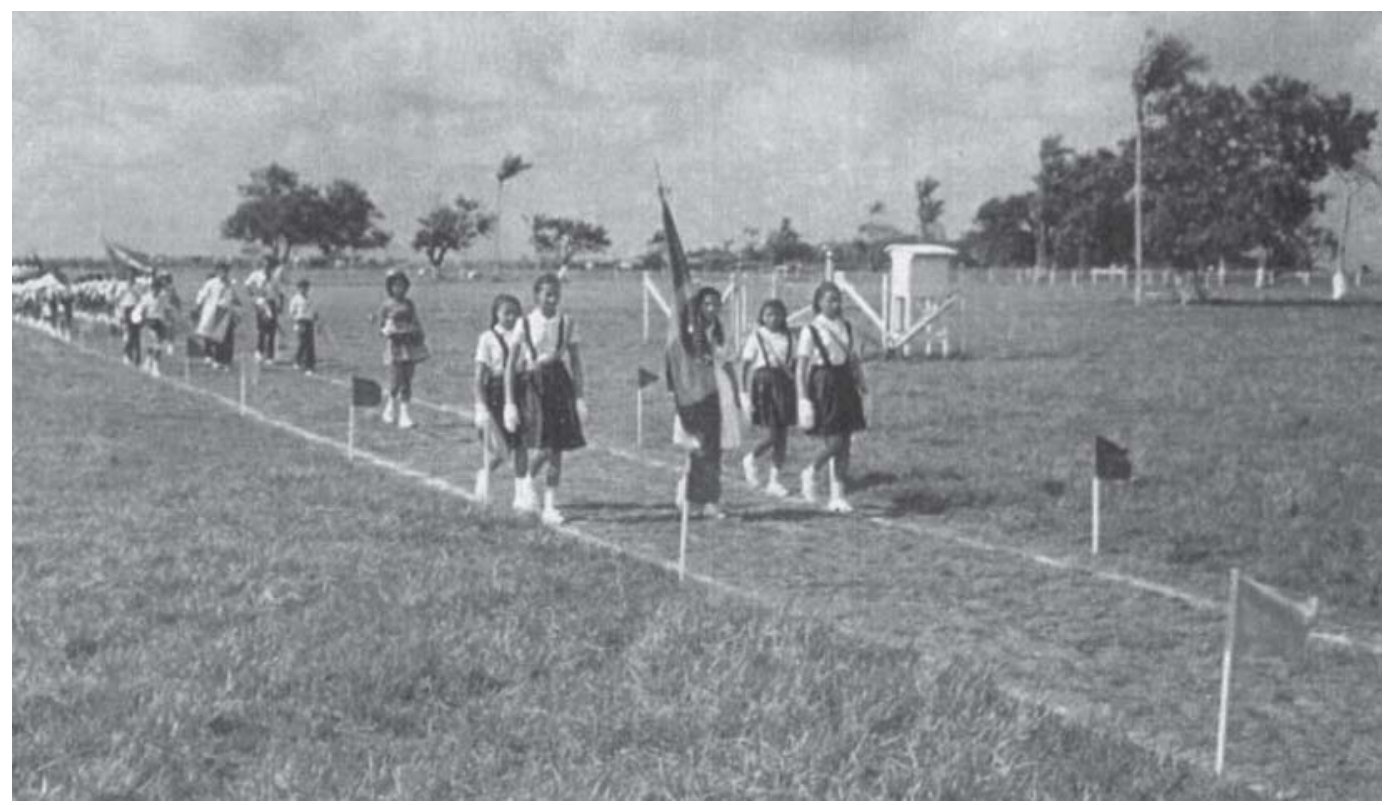

Figura 1: Desfile de 7 de Setembro dos alunos na fazenda Tapera, na cidade de Soure (PA), s.d.; foto de autoria desconhecida (Arquivos da fazenda Tapera) 
Portanto, as escolas foram inicialmente instituídas por dona Dita e seu Domingos, quando eles eram "donos de tudo aquilo ali". Em seguida, outros fazendeiros reproduziram a prática, sobretudo porque ela garantia certo prestígio na região e, por extensão, ganhos eleitorais.

Dona Dita transformou sua escola da fazenda Tapera em um grande feito no interior de Soure. As festas escolares eram todas caprichosamente organizadas por ela, e algumas se transformaram em tradição na região, como a do 7 de Setembro, que recebia a visita de políticos ilustres, secretários e técnicos do governo. Dona Dita afirmou que ela e o marido eram "muito bem situados junto ao governo", e explicou: "Quem me ajudou muito ..., por duas vezes, foi o governador ..., o coronel Alacid ... E ele ... uma vez me telefonou e disse: 'Olha, Dita, eu vou levar o secretário de Educação para tua festa do 7 de Setembro'”.

O poder público e os proprietários da Tapera sempre estiveram juntos. No arquivo da fazenda, onde encontramos os livros de visitas e uma coleção de recortes de jornais com matérias a seu respeito, está atestada a presença constante de secretários de Educação, técnicos do Ministério da Educação e membros do Conselho Estadual de Educação, entre eles a professora Ruth Costa, que foi delegada do MEC e secretária de Educação do estado do Pará e com quem dona Dita mantinha fortes laços de amizade.

Em 1974 o presidente Ernesto Geisel visitou o Pará, foi à ilha de Marajó e conheceu a fazenda Santa Cruz da Tapera. Lançou então o Programa de Polos Agropecuários da Amazônia (Poloamazonia), que previa investimentos em projetos de desenvolvimento agropecuário e de mineração.

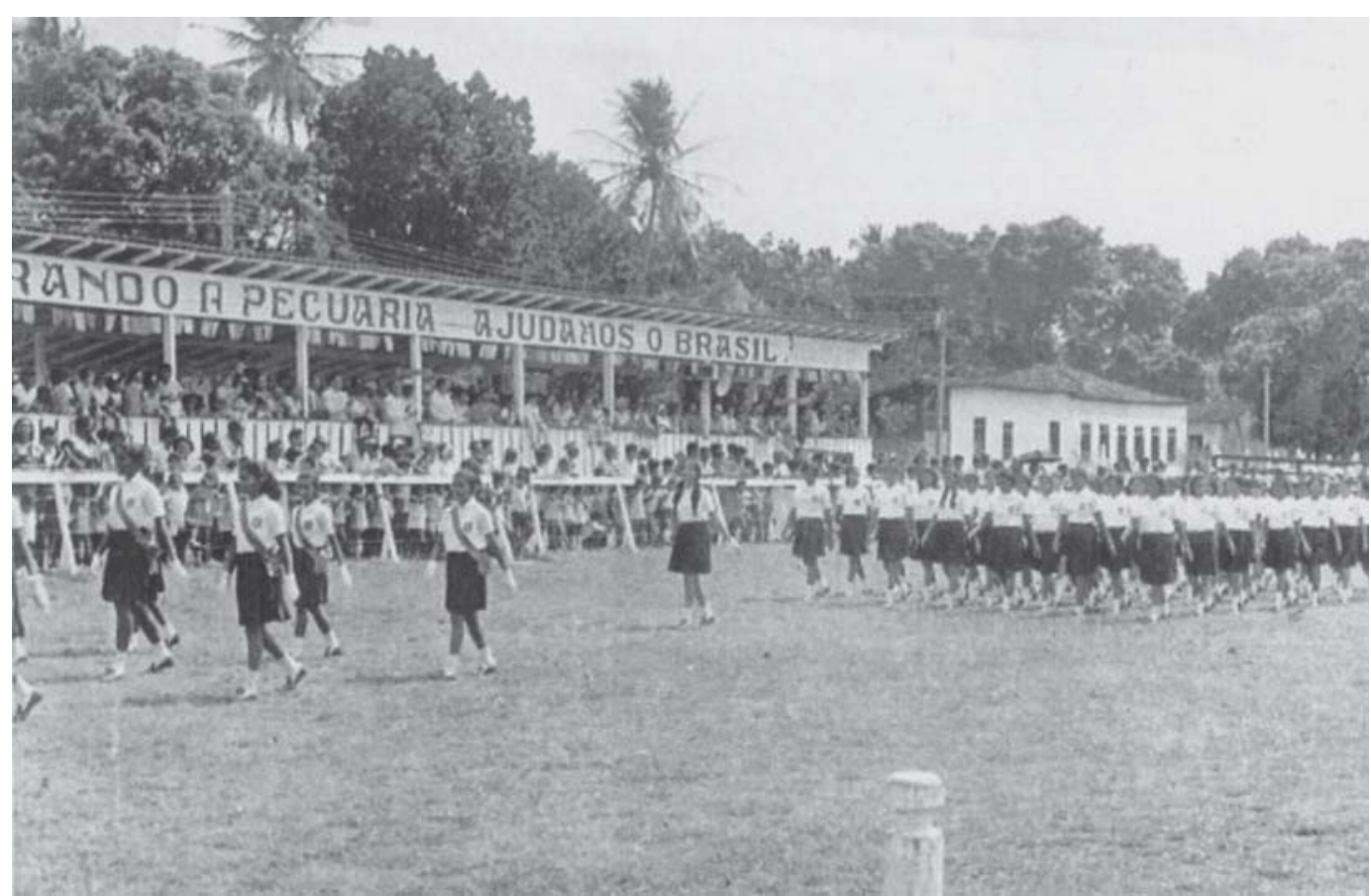

Figura 2: Desfile dos alunos da escola da fazenda Tapera, em homenagem ao 7 de Setembro, cidade de Soure (PA), s.d.; foto de autoria desconhecida (Arquivo da fazenda Tapera) 
A relação política de seu Domingos e dona Dita com o poder público demonstra a proximidade dos fazendeiros com o estado e o município, bem como a maneira de esses proprietários lidarem com o poder. Alguns deles, aliás, estiveram à frente da administração pública ao assumir a prefeitura do município de Soure, como Rodolfo Fernando Engelhard (1953-1957, 1958-1961), Alberto David Fadul (1971-1972), Carlos Nunes Gouvêa (19771982, 1989-1992) e Raimundo Carlos Vitelli Cassiano (1983-1988); o mandato de deputado estadual, como Francisco Lobato, já falecido, cujos filhos são os atuais proprietários da fazenda Matinadas; e os de governador e vice-governador do estado, como Alacid Nunes e seu filho, proprietários da fazenda Alacilândia.

A fazenda Tapera era muito visitada por autoridades. O governador Alacid Nunes, ressalta a professora Tereza, "todo 7 de Setembro fazia a abertura do desfile em Belém. Depois pegava um avião e, juntamente com o secretário de Educação e o delegado do MEC, ia assistir ao desfile da Tapera".

Nos arquivos da fazenda, encontra-se o discurso proferido pelo secretário de Educação do Estado por ocasião da inauguração do prédio escolar que dona Dita e seu Domingos construíram, no início da década de 1980, e denominaram Escola de Primeiro Grau Doutor Domingos Acatauassu Nunes - uma condição do governo para apoiar o funcionamento desse segmento escolar.

Muitas práticas até então estranhas ao lugar foram aos poucos instituídas pela escola 'concedida'. Naquela fazenda do interior de Soure estabeleceram-se novos valores, sedimentaram-se outras relações, viabilizaram-se recursos a suas gentes. Agora - orgulhavam-se todos - não havia vaqueiro naquelas redondezas que não soubesse ler e escrever. Dona Dita tinha constituído escolas na sede da fazenda Tapera, nos retiros São Lourenço, Flecheiras, Aruãs e Filhos de Eva, como também na fazenda Maria dos Anjos, que não fazia parte do espólio da Tapera.

A partir de 11 de dezembro de 2000, com base na resolução 813 do Conselho Estadual de Educação do Pará, as escolas de fazenda passaram a funcionar sob o regime do sistema de nucleação ou escola anexa, em que escolas da capital ou dos municípios do estado

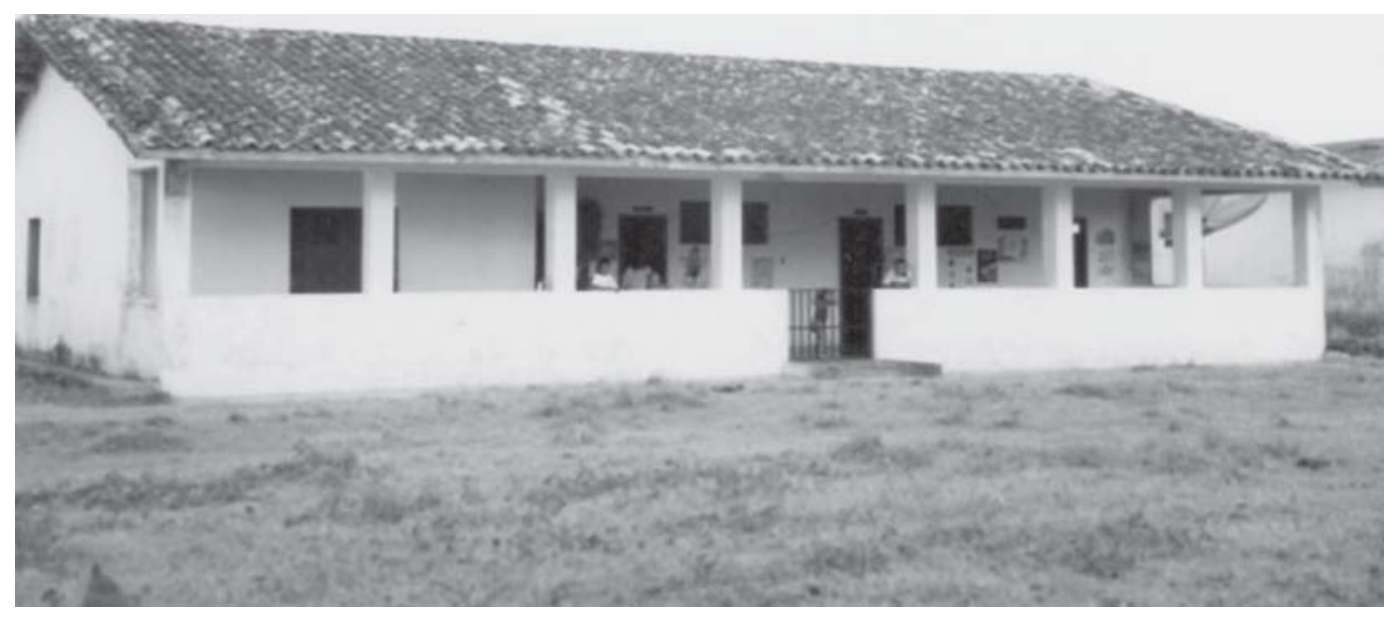

Figura 3: Escola Doutor Domingos Acatauassu Nunes, da fazenda Tapera, cidade de Soure (PA), s.d.; foto de autoria desconhecida (Arquivo da fazenda Tapera) 
funcionam sob uma única responsabilidade administrativa e vinculam-se pedagógica e tecnicamente a uma escola-matriz, de onde são expedidas diretrizes curriculares e normativas gerais.

As escolas das fazendas Tapera, Matinadas e São Lourenço foram construídas pelos proprietários. As de Flecheiras e São Bento funcionam na casa das professoras, esposas dos vaqueiros. A de Cuieiras funcionava num barracão construído anexo à casa de uma sitiante da comunidade.

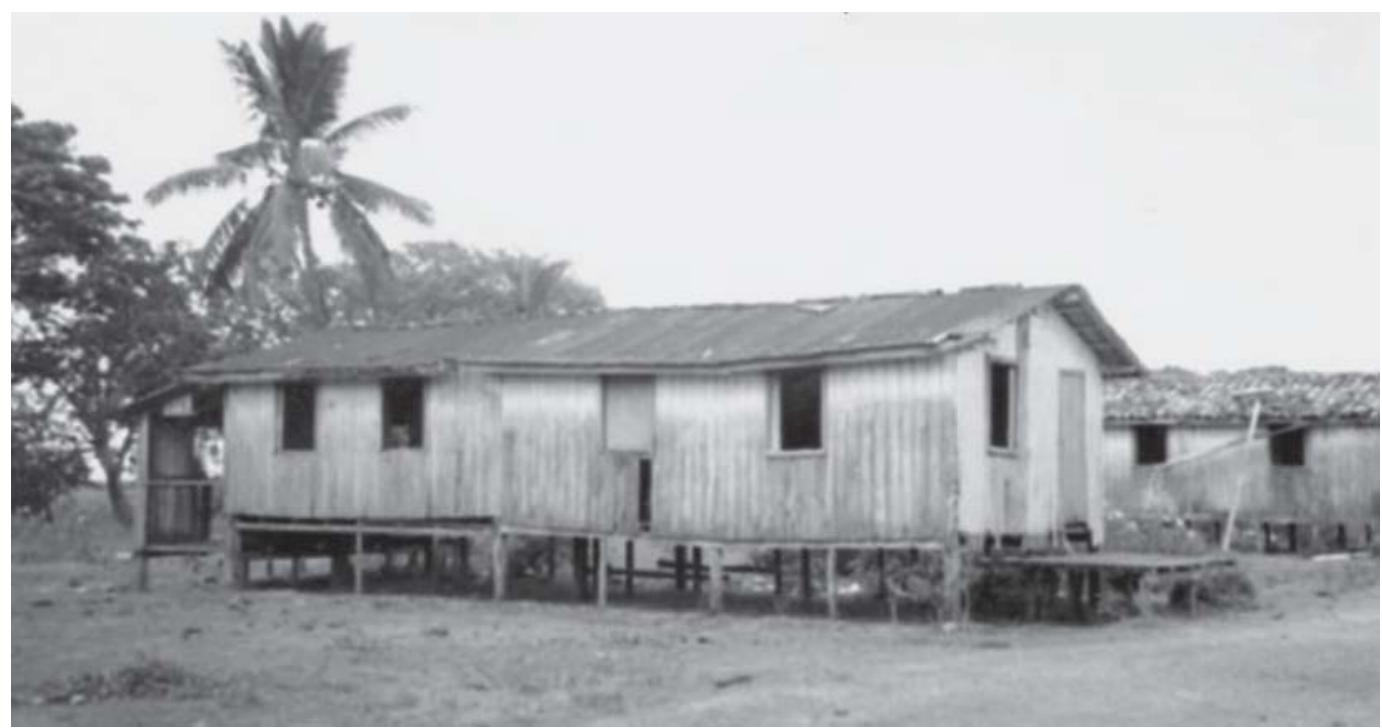

Figura 4: Escola (anexa) Municipal de Ensino Fundamental São Francisco, da fazenda Matinadas, na cidade de Soure (PA), 2001; foto, Sonia Araújo

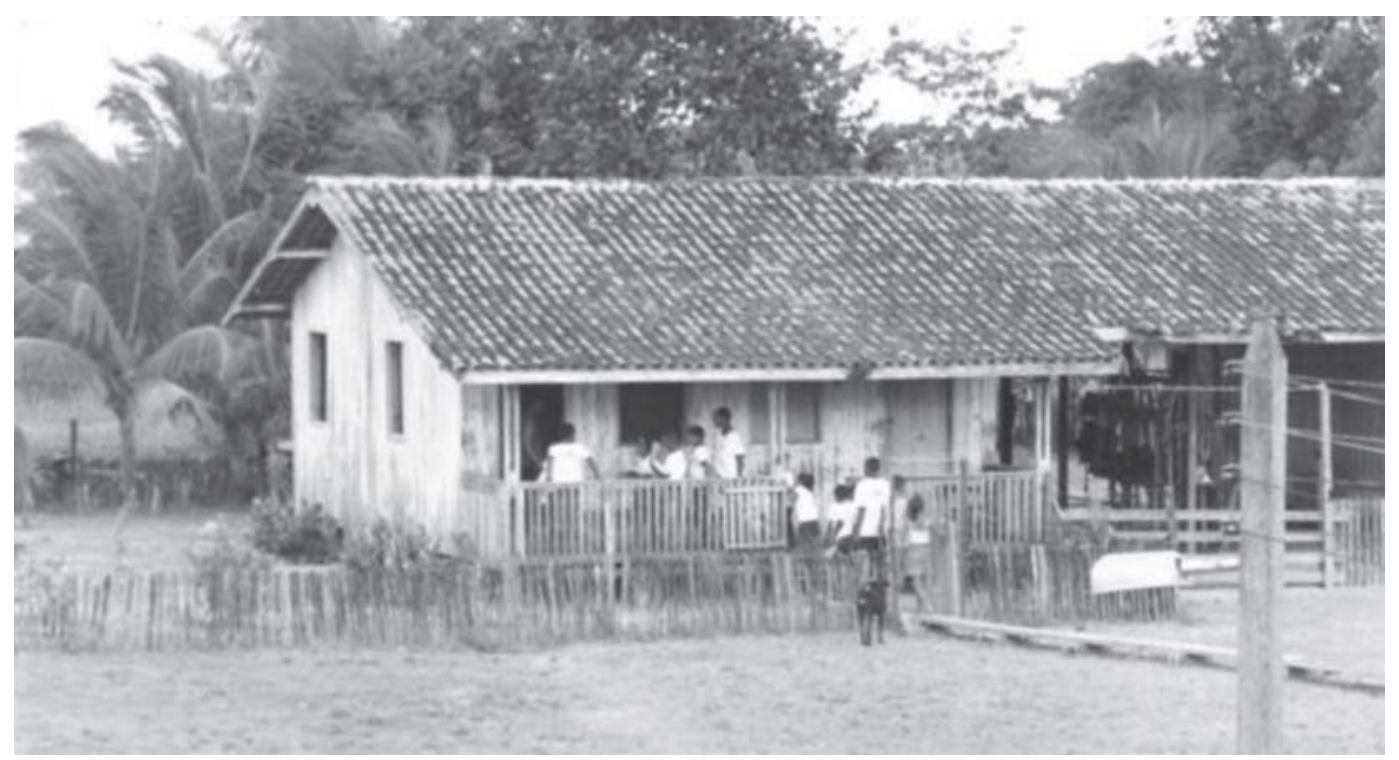

Figura 5: Escola (subanexa) da fazenda São Lourenço, também de propriedade da família Acatauassu, na cidade de Soure (PA), 2001; foto, Sonia Araújo 


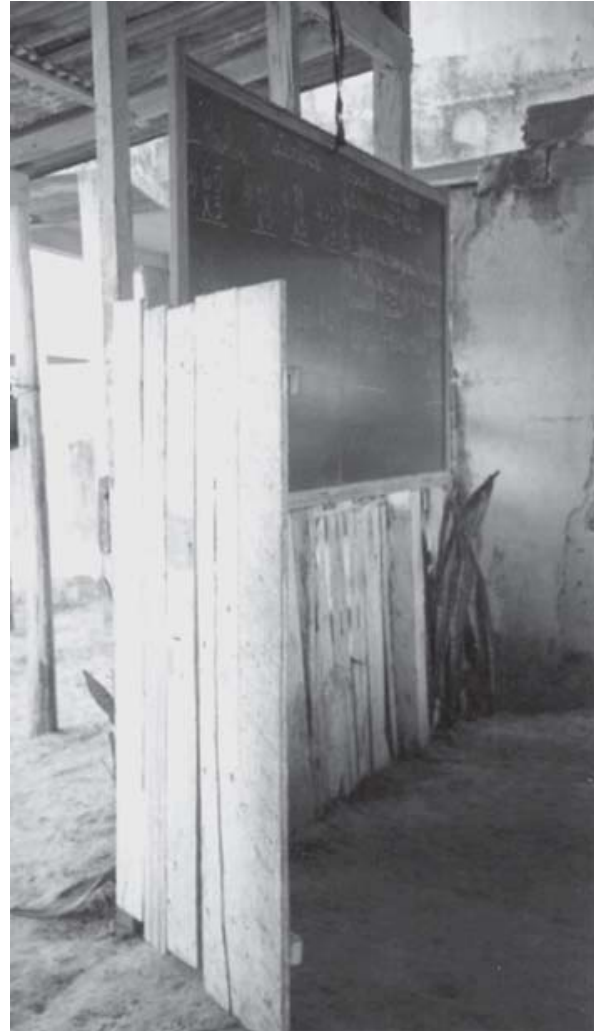

Figura 6: Sala de aula da Escola de Cuieiras, na cidade de Soure (PA), 2001; foto, Sonia Araújo

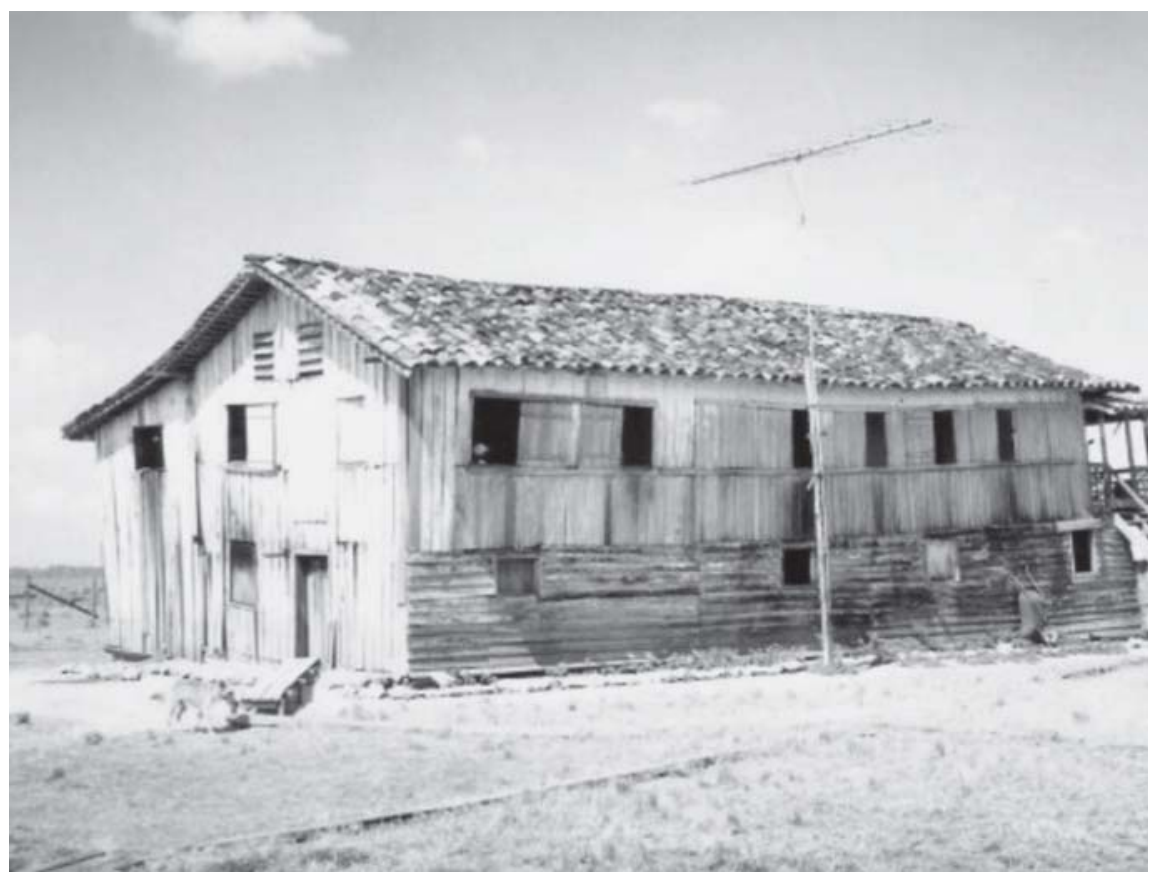

Figura 7: Escola da fazenda São Bento, na cidade de Soure (PA), 2001; foto, Sonia Araújo

As escolas situam-se na vila de casas da fazenda, o que faz com que se tornem uma extensão do ambiente familiar da professora e dos alunos. No caso de uma delas - a da fazenda Flecheiras, localizada no retiro da ilha da Roça -, algumas crianças se deslocam da sede para lá montadas em búfalos ou cavalos. Já na escola de Cuieiras, são a professora e o professor que se deslocam de lugares distantes em direção à escola, ora a cavalo, ora por barco.

A escola de fazenda em Marajó é uma instituição 'concedida'. Suas imagens revelam cartazes, lousas mal fixadas, livros didáticos amarelados e rabiscados, carteiras quebradas e sem encosto, santos cuidadosamente colocados sobre um armário ou uma prateleira, potes com água não tratada, prédios sem paredes, banheiros sem fossa e sem água encanada, intervalos sem merenda.

\section{Considerações finais}

As escolas nas fazendas da ilha de Marajó, município de Soure, são demonstração das relações de apropriação e violência da modernidade, tal como explica Santos (s.d.). Ainda que a esta altura não caiba mais responsabilizar a colonização pelas relações de subjugação ainda presentes no Norte do Brasil, é impossível pensá-las sem uma perspectiva histórica, que considere as transformações por que passou a região desde a invasão da América, como bem ressalta Dussel (2005). Entendemos, portanto, que as condições de escolarização em que se encontravam submetidas, e ainda se encontram, as crianças de Marajó, resultam desse processo histórico, em cuja origem se encontram as relações entre brancos e indígenas. 


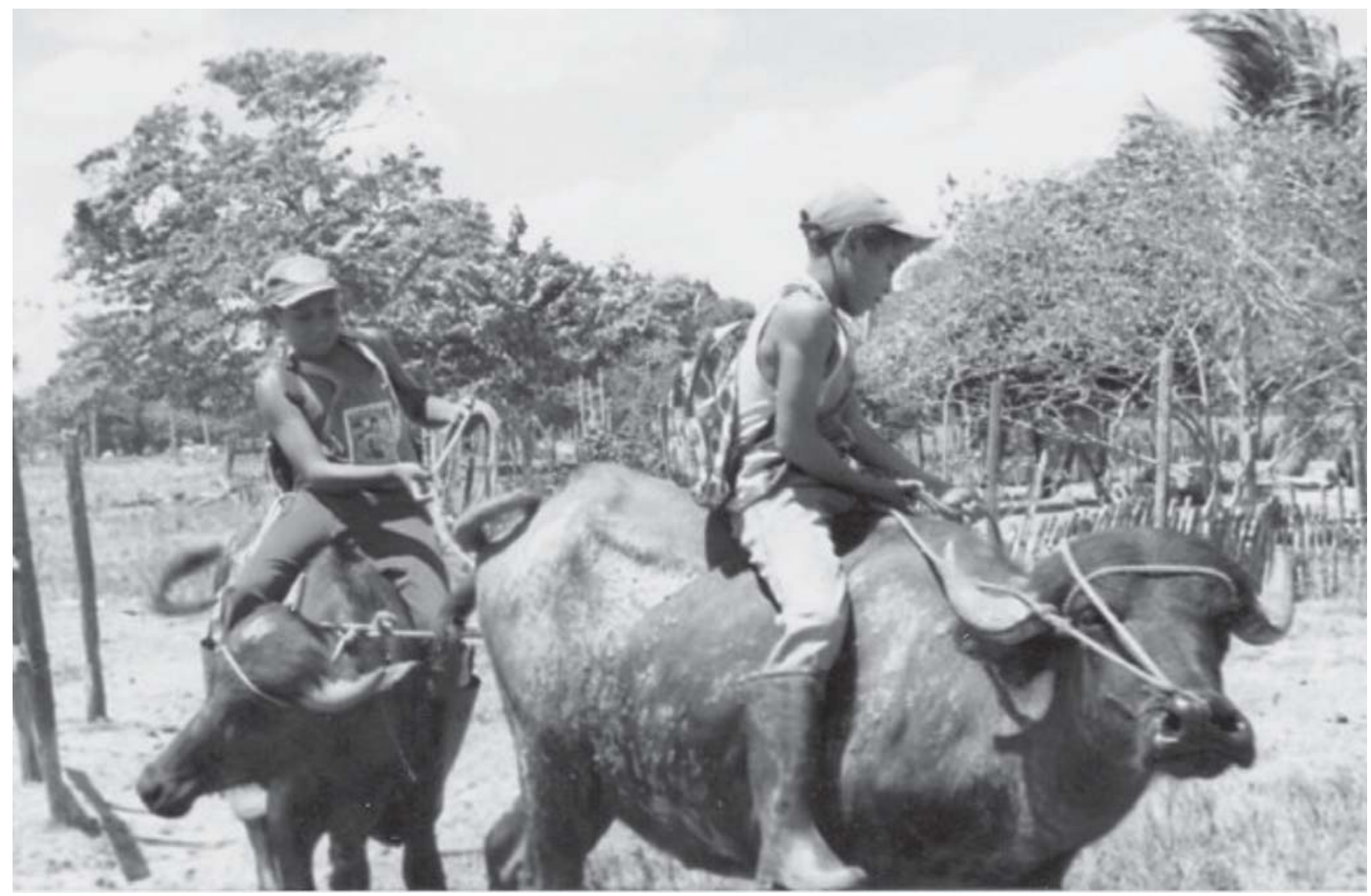

Figura 8: Alunos chegando à Escola de Flecheiras, na cidade de Soure (PA), 2001; foto, Sonia Araújo

As condições físicas dessas escolas revelam o quanto a saúde das crianças se encontra em risco. Chegamos a observar salas de aula em que os alunos dividiam o espaço com animais domésticos, portanto sem as mínimas condições ambientais necessárias ao aprendizado de qualidade. As boas intenções de professores em tentar oferecer escolarização às crianças não são suficientes para garantir a estas os direitos que lhes devem ser assegurados, pois alterar o atual estado das coisas está muito além de seu alcance. As relações entre poder público e economia, além das estratégias dos fazendeiros no sentido de dificultar a articulação dos professores, se dão de forma tal que as gentes de Marajó se tornam reféns de todo um sistema de expropriação da cidadania.

As condições de vida das famílias dos vaqueiros e a escola que têm denotam a omissão do Estado quanto à educação pública de qualidade para as crianças de Marajó, contrariando a Lei de Diretrizes e Bases da Educação Nacional. A escola é, como foi no passado, concessão com a finalidade clara de manter os vaqueiros naquele lugar, sob condições precárias de trabalho e subsistência; é o último recurso do adventício para a manutenção do subjugo. Não é um bem público, pois se encontra situada em espaço privado e sob a tutela do fazendeiro. A situação de Marajó revela uma ampla violação dos direitos humanos. As necessidades coletivas transformam-se, como tudo (ou quase tudo), em necessidades privadas; as reivindicações, em pedidos; e os direitos, em doações.

\section{NOTAS}

${ }^{1}$ Em 1995 a Secretaria de Inspeção do Trabalho do Ministério do Trabalho criou o Grupo Especial de Fiscalização Móvel (GEFM) e o Grupo Executivo de Repressão ao Trabalho Escravo (Gertraf) para combater 
o trabalho escravo no país. Em 2003 o governo federal lançou o Plano Nacional para a Erradicação do Trabalho Escravo, abrangendo 76 ações que expressam e articulam os papéis dos entes públicos e da sociedade civil no enfrentamento do problema. Ainda em 2003 o presidente da República criou a Comissão Nacional para a Erradicação do Trabalho Escravo (Conatrae). Em 11 anos de atuação, o GEFM fiscalizou 1.591 imóveis rurais e libertou 20.763 trabalhadores. O Ministério do Trabalho e Emprego criou, pela portaria 540, de 15 de outubro de 2004, o Cadastro de Empregadores, formado por pessoas físicas e jurídicas colhidas pela fiscalização na prática do trabalho escravo ou análogo à escravidão. Conhecido como Lista Suja, o cadastro é atualizado semestralmente e encaminhado aos ministérios da Fazenda, da Integração Nacional, do Desenvolvimento Agrário, do Meio Ambiente e à Secretaria Especial dos Direitos Humanos, a fim de que cada instituição adote as medidas oportunas em seu respectivo âmbito de competência. Em dezembro de 2003 foi sancionada, pelo presidente da República, a lei 10.803, que altera o Código Penal e estabelece pena de dois a oito anos, além de multa, a pessoas que mantenham trabalhadores em condição análoga à de escravo em suas propriedades.

${ }^{2}$ Conforme denúncia feita pelo bispo, num trecho do rio Tajapuru, às margens dos municípios de Breves e Melgaço, "meninos e meninas de 12 a 16 anos aproveitam o percurso das balsas para subir nas embarcações e se prostituir em troca de carne ou óleo de cozinha" (Estado está ingovernável, 15 abr. 2008). Dados sobre as medidas tomadas pelo Ministério Público do Estado do Pará podem ser conferidas no site do órgão (http://www.mp.pa.gov.br/not07051600.php).

${ }^{3}$ A violência relacionada a essa matéria impede que estudos científicos deem conta de números e descrevam esse processo de forma mais consistente. Amedrontada com o poder das madeireiras, a população muitas vezes se recusa a dar depoimentos. O Greenpeace, com base em dados jornalísticos, testemunhos e opiniões de especialistas, publicou relatório sobre o tema (Greenpeace, 2003).

${ }^{4}$ Já houve mais escolas nas fazendas de Soure, especialmente na década de 1970, quando os fazendeiros gozavam do apoio político e econômico do poder público, como nas seguintes fazendas: Aruãs, de propriedade de Paulo Acatauassu; Araraquara, da família Sarmento; Bom Jardim, de Eduardo Ribeiro; Bela Vista, de Solange Santos; Boa Esperança, de Jaime Penna; Camburupi, de Alacid Nunes; Filhos de Eva, pertencente a Filhos de Eva Agropecuária Ltda.; Gilva, de Leandro Penna; Laranjeiras, de Moises Isaac Benchimol; Maria dos Anjos, de Antonio Roberto Fonseca; Ribanceira, de Rosa Lobato Ledoure; Ritlândia, pertencente à Fazenda Amaraji Ltda.; Santa Maria, de Ovídio Lobato; e Tartarugas, de Guilherme M. Lobato.

${ }^{5}$ Inspirada na ideia de sujeitamento do sujeito, de Foucault $(1971,1986)$, e na interpretação filológica de Said (2007), compreendemos que o caboclo é invenção construída durante a colonização e disseminada enfaticamente a partir do ciclo da borracha, com o intuito de desqualificar homens, mulheres e crianças da floresta. Trata-se de classificação elaborada com base numa visão etnocêntrica da humanidade, fundamentada na teoria da raça. Identificando os viventes da floresta amazônica como caboclos, depreciase 'o outro' e desqualificam-se as diferenças culturais.

${ }^{6}$ Segundo Galvão (1962), viveram no arquipélago cinco tipos humanos indígenas: Ananatuba, primeira fase; Mangueira, segunda fase; Formiga, terceira fase; Marajoara, quarta fase; Aruã, quinta e última fase. Deles, os Marajoara, que viveram na parte ocidental do lago Arari e cujas aldeias e cemitérios ficavam nos campos, sobre aterros artificiais, foram os mais desenvolvidos. Os Aruã subsistiram até aproximadamente 1820.

${ }^{7}$ Tesos são aterros artificiais preparados pelos índios para abrigar suas urnas funerárias. Muitos materiais arqueológicos já foram desenterrados nesses tesos. Durante a pesquisa de campo registramos, por fotografia, o achado de centenas de peças que se encontravam abandonadas nas fazendas. Para Heloisa Torres (1940,1937), os tesos são mounds funerários que abrigam peças raras prensadas, destruídas pelas patas dos búfalos, que nas cheias sazonais dos campos de Marajó sobem para as partes mais altas da ilha.

${ }^{8}$ Entrevista com dona Dita, proprietária da fazenda Santa Cruz da Tapera, em Belém, em 11 de novembro de 2001. Todas as transcrições de seu depoimento, neste artigo, fazem parte dessa entrevista.

${ }^{9}$ O sistema de transmissão de sesmarias iniciou-se, no Brasil, em 1530, com a carta régia de 20 de novembro, que estabelecia: "e das que assim der as ditas pessoas lhes passará suas cartas declarado nelas como lhes dá em suas vidas somente e que de dentro em seis anos do dia da dita data cada um aproveita a sua e se no dito tempo assim o não fizer as poderá tornar a dar com as mesmas condições a outras pessoas que as aproveitar". Apesar da falta de limites na concessão de terras, as cartas régias de 27 de dezembro de 1695 e 7 de dezembro de 1697 limitavam a doação. A primeira recomendava que não se concedesse a cada morador "mais de quatro léguas de comprimento e uma de largo". A segunda determinava concederem-se apenas "três léguas ao comprimento e uma de largo". No século XVIII, a 
provisão de 19 de maio de 1729 limitou a concessão de sesmaria a "três léguas de comprimento a uma de largo, ou a três de largura e uma de comprimento". O decreto de 20 de outubro de 1753 determinava que não se confirmassem as sesmarias sem a "necessária medição e demarcação de terras". O latifúndio no Brasil e o exemplo de Marajó demonstram, com evidência, que essas últimas medidas não foram executadas.

${ }^{10}$ Retiros são pequenos sítios em que moram os vaqueiros da fazenda com suas famílias, localizados estrategicamente nas extremidades das propriedades, para protegê-las de invasão, funcionando como uma espécie de postos avançados. Identificamos, em Brown (1996), que tal estratégia já fazia parte do sistema agrícola colonial, quando os roceiros funcionavam como vigias dos limites das fazendas grandes e como tropas de choque da colonização na fronteira, fazendo o trabalho perigoso de derrubar a floresta antes de serem expulsos da terra.

${ }^{11}$ Entrevista feita em 14 de novembro de 2001, com a professora Tereza, hoje aposentada e uma das primeiras a lecionar na fazenda Tapera, em Soure. A outra transcrição de seu depoimento, neste artigo, faz parte da mesma entrevista.

\section{REFERÊNCIAS}

BARTHES, Roland.

O óbvio e o obtuso: ensaios críticos III. Rio de Janeiro: Nova Fronteira. 1990.

BURKE, Peter.

Testemunha ocular: história e imagem. Bauru: EdUSC. 2004.

BROWN, Larissa V.

Plantações, pastos e portos: a economia colonial e mudanças ambientais no Brasil. In: Azevedo, Francisca L. Nogueira; Monteiro, John Manuel (Org). Raízes da América Latina. São Paulo: EdUSP. p.245-260. 1996.

CANCLINI, Nestor Garcia.

Culturas híbridas: estratégias para entrar e sair da modernidade. São Paulo: EdUSP. 1998.

CRULS, Gastão Luís.

Hiléia amazônica. 2. ed. São Paulo: Companhia Editora Nacional. 1955.

DIÉGUES JÚNIOR, Manuel.

Populações rurais brasileiras. In: Szmrecsány, Tamás; Queda, Oriovaldo (Ed.). Vida rural e mudança social. São Paulo: Editora Nacional. p.121-131. 1979.

DIÉGUES JÚNIOR, Manuel.

Regiões culturais do Brasil. Série 6, v.2. Rio de Janeiro: Inep. 1960.

DUSSEL, Enrique.

Filosofia da libertação: crítica à ideologia da exclusão. São Paulo: Pulus. 2005.

ESTADO ESTÁ INGOVERNÁVEL.

O Liberal, Belém. Disponível em: http:// www.orm.com.br/oliberal. Acesso em: $15 \mathrm{dez}$. 2010. 15 abr. 2008.

EVANS, Clifford; MEGGERS, Betty. Archaelogical investigations at the mouth of the Amazon. Bureau of American Ethnology Bulletin, Washington, n.167. 1957.
FOUCAULT, Michel.

A arqueologia do saber. Rio de Janeiro: Forense Universitária. 1986.

FOUCAULT, Michel.

Sobre a arqueologia das ciências (resposta ao círculo epistemológico). In: Foucault, Michel et al. Estruturalismo e teoria da linguagem.

Petrópolis: Vozes. p.9-55. 1971.

FREIRE, Paulo.

Educação como prática da liberdade. Rio de Janeiro: Paz e Terra. 1977.

GALVÃO, Eduardo.

Encontro e sociedades: índios e brancos no Brasil. Rio de Janeiro: Paz e Terra. 1979.

GALVÃO, Eduardo.

Encontro de sociedades tribal e nacional. Manaus: Secretaria de Imprensa e Divulgação do Governo do Estado do Amazonas. 1966.

GALVÃO, Eduardo.

Guia de exposições de antropologia. Belém: Museu Paraense Emílio Goeldi. (Série Guias, n. 1). 1962.

\section{GREENPEACE.}

Estado de conflito: uma investigação sobre grileiros, madeireiros e fronteiras sem lei no Estado do Pará e Amazonas". S.l.: Greenpeace. Disponível em: http://www.greenpeace.org.br/ amazonia/pdf/para_estadodeconflito.pdf. Acesso em: 15 dez. 2010. 2003.

LEONARDI, Victor.

Entre árvores e esquecimentos: história social nos sertões do Brasil. Brasília: Paralelo 15. 1996.

MAUAD, Ana Maria.

Fotografia e história, possibilidades de análise. In: Ciavatta, Maria; Alves, Nilda (Org.). A leitura de imagens na pesquisa educacional: história, comunicação e educação. 2.ed. São Paulo: Cortez. p.9-36. 2008. 
MIRANDA NETO.

Marajó: desafio da Amazônia. São Paulo: Record. 1976.

MORAES, Raymundo.

Amphitheatro amazônico. São Paulo: Companhia Melhoramentos. 1936.

OIT.

Organização Internacional do Trabalho. Trabalho escravo no Brasil do século XXI. Brasília: OIT. Disponível em: http://www.oitbrasil. org.br/download/sakamoto_final.pdf. Acesso em: 10 dez. 2010. 2005.

SAID, Edward W.

Orientalismo: o Oriente como invenção do Ocidente. São Paulo: Companhia das Letras. 2007.

SALLES, Vicente.

O negro no Pará sob o regime da escravidão. Rio de Janeiro: Fundação Getulio Vargas. 1971.

SANTOS, Boaventura de Souza.

Para além do pensamento abissal: das linhas globais a uma ecologia dos saberes. Disponível em: http://www.ces.uc.pt/documentos/ para_alem_do_pensamento_abissalRCCS78.pdf. Acesso em : 6 fev. 2008. s.d.
TORRES, Heloísa Alberto.

Arte indígena na Amazônia. Rio de Janeiro: Ministério da Educação e Saúde. (Publicações do SPHAN, 60). 1940.

TORRES, Heloísa Alberto.

Contribuições para o estudo da proteção ao material arqueológico e etnográfico no Brasil. Revista do Serviço do Patrimônio Histórico e Artístico Nacional, Rio de Janeiro, n.1, p.9-30. 1937.

\section{UNICEF.}

Fundo das Nações Unidas Para a Infância. Situação mundial da infância 2008: Caderno Brasil. Brasília: Unicef. Disponível em: http:// www.unicef.org/brazil/pt/caderno brasil2008.pdf. Acesso em: 15 dez. 2010. 2008.

WILLIAMS, Raymond.

Resources of hope: culture, democracy, socialism. London: Verso. 1989.

WILLIAMS, Raymond.

The long revolution. London: Chatto \& Windus. 1961. 